\title{
Mitochondrial damage in hippocampal neurons of rats with epileptic protein expression of Fas and caspase-3
}

\author{
JUNQIANG FENG ${ }^{1}$, LIFANG FENG ${ }^{2}$ and GUIRU ZHANG ${ }^{3}$
}

\author{
${ }^{1}$ Department of Neurology, Daqing Longnan Hospital, Daqing, Heilongjiang 163453; ${ }^{2}$ Department of \\ Family Practice, Binzhou People's Hospital, Binzhou, Shandong 256600; ${ }^{3}$ Department of Neurology, \\ Shandong Provincial Hospital Affiliated to Shandong University, Jinan, Shandong 250022, P.R. China
}

Received December 14, 2017; Accepted June 13, 2018

DOI: $10.3892 /$ etm.2018.6439

\begin{abstract}
Epilepsy model in rats was established to observe the behavior and pathological changes, and to detect mitochondrial dysfunction, exploring its possible molecular mechanisms. The epileptic status of Sprague-Dawley (SD) rats was induced by intraperitoneal injection of lithium chloride, and the change of behavior was recorded. Electroencephalogram (EEG) was used to measure the abnormal discharge of neurons in rats. The brain tissue was fixed with polyformaldehyde and the paraffin sections were prepared, and the damage of the hippocampal neurons was observed with Nissl staining. Mitochondrial ATP and mitochondrial DNA were examined to assess mitochondrial dysfunction. Finally, qPCR and western blot analysis were used to detect mRNA and protein expression of fatty acid synthetase (Fas), Fas ligand (FasL) and caspase-3 in rat hippocampal neurons. The correlation between the mitochondrial dysfunction of rat hippocampal neurons and Fas and caspase-3 was analyzed. Compared with the normal group rats, the model group showed typical seizures, which were determined by the Racine attack score. EEG of the hippocampus of the model group was recorded in cluster in model group rats. Nissl staining showed a different degree of damage to the hippocampal neurons in the model group compared with normal rats. The mitochondrial ATP content and DNA content of rat hippocampal neurons in the model group were significantly lower than that of normal rats $(\mathrm{P}<0.01)$. The $\mathrm{qPCR}$ and western blot results showed that the mRNA and protein expression levels of Fas, FasL and caspase-3 were significantly increased in the hippocampus of rat model group $(\mathrm{P}<0.01)$. The expression level of Fas and caspase-3 in hippocampal tissues of rats was negatively correlated with mitochondrial DNA content. In conclusion, seizures cause damage of neuron mitochondria in rat hippocampus
\end{abstract}

Correspondence to: Dr Guiru Zhang, Department of Neurology, Shandong Provincial Hospital Affiliated to Shandong University, 4 Duanxingxi Road, Huaiyin, Jinan, Shandong 250022, P.R. China E-mail: azx116f@163.com

Key words: epileptic, hippocampal neurons, mitochondria leading to death of hippocampal neurons, the mitochondrial damage of hippocampal neurons in epileptic rats was closely related to the expression of Fas and caspase-3.

\section{Introduction}

Epilepsy is a chronic brain disease commonly found in clinical practice, which can occur due to combined action of various factors. Epidemiological studies have found that the incidence of epilepsy shows an upward trend year by year, and China is also a high-incidence area of epilepsy, where nearly half of epileptic patients have refractory epilepsy $(1,2)$. At present, the main treatment for epilepsy is drug therapy, and more than 10 kinds of first-line antiepileptic drugs are used in the clinic. However, many epilepsy types cannot be effectively controlled, leading to serious financial burden on both the patients and society (3). The onset of epilepsy generally includes three processes, namely, epileptic brain injury, epileptic seizure latency and recurrence of epilepsy (4). The occurrence of epilepsy involves a variety of molecular, cellular and neuronal changes, and the intervention in relevant molecular pathways involved in the occurrence of epilepsy can effectively prevent the incidence of epilepsy, reducing the exaltation of neurons (5).

Controlling and reducing the early onset of epilepsy is able to effectively prevent the recurrence of epilepsy later and reduce the damage caused by epilepsy to the cognitive and memory functions in patients (6). A study by Bowen et al (7) found that patients with epilepsy have a certain degree of cognitive, learning and memory impairment, which may be closely related to the damage in hippocampal neurons, and a study by Bardai et al (8) discovered that the excitability of hippocampal neurons is correlated with synaptic plasticity, the formation of a new synapsis is sure to build up an excited loop that can significantly increase the sensitivity of epileptic seizures, but increased synaptic plasticity will lead to neuronal death. Mitochondrion plays an important role in the process of apoptosis. A large number of studies have proven that mitochondrial dysfunction often occurs in neurons of brain tissues with various diseases such as cerebral ischemia, depression and Parkinson's disease, and is closely associated with secondary damage occurring after cerebral ischemia; mitochondrion is involved in the energy metabolism of 
eukaryotes, and mitochondrial damage will lead to significant reduction in its production capacity, resulting in insufficient energy supply in cells $(9,10)$. A study by McFarland et al (11) found that epileptic seizures can lead to a certain degree of damage to mitochondrial functions, but the mechanism has not been studied. This study explored the relationship between the occurrence of epilepsy and the mitochondrial damage in hippocampal neurons and the possible molecular mechanism by establishing rat models of epilepsy.

\section{Materials and methods}

Animals and grouping. A total of 30 male Sprague-Dawley (SD) rats weighing 250-280 g were purchased from Guangdong Medical Laboratory Animal Center (experimental animal production license number SCXK 2016-0002). These rats were raised in a specific pathogen-free (SPF) animal room at $22-27^{\circ} \mathrm{C}$, with a humidity of $50-60 \%$ and a $12 \mathrm{~h}$ light $/ 12 \mathrm{~h}$ dark cycle. All animals had free access to food and water. After adapting to SPF environment for one week, SD rats were randomly divided into normal group $(n=15)$ and model group $(n=15)$, and pretreated with lithium chloride (intraperitoneal injection) at $24 \mathrm{~h}$ before experiment. During the experiment, rats in model group were given pilocarpine $(30 \mathrm{mg} / \mathrm{kg})$ to establish rat models of epilepsy. After $60 \mathrm{~min}$ of epileptic seizures, rats in model group were intraperitoneally injected with diazepam $(10 \mathrm{mg} / \mathrm{kg})$ to terminate reaction, and rats in normal group were injected with the same dose of saline.

The provisions for experimental animals in the Guide for the Care and Use of Laboratory Animals by the National Research Council were strictly abided in all operations on animals. The experimental scheme was approved by the Experimental Animal Ethics Committee in Daqing Longnan Hospital (Daqing, China).

Determination of epileptiform behavior. After modeling, behavioral changes of rats in the control and model groups were recorded. The onset of epilepsy was determined via the Racine seizure scale, namely, no abnormalities such as convulsion were observed: level 0; regular chewing and blinking, and convulsions of mouth and face were found: level I; spastic movement was found in head and neck: level II; unilateral forelimb convulsion was found, without hind limb erection: level III; bilateral forelimb convulsion combined with body erection was observed: level IV; orthotonos, dorsiflexion, falling down and general tetany-clonus were found: level V. Levels IV-V were considered as epileptic seizures, and modeling was successful. During epileptic seizures, electroencephalogram (EEG) was used to record the brain waves of hippocampus of rats in two groups to observe the presence of cluster spike discharge: rats in two groups were anesthetized and placed on a brain solid positioner to expose the skull and bregma, and then electrodes were inserted into the hippocampi of rats $(3.8 \mathrm{~mm}$ away from the bregma, $2 \mathrm{~mm}$ beside the midline, and $5 \mathrm{~mm}$ under the dura mater), and the reference electrode was placed subcutaneously on the counter mastoid.

Nissal staining. After behavioral detection, each rat in the two groups was anesthetized, its thoracic cavity was opened to expose the heart, and then cardiac perfusion was performed with $100 \mathrm{ml}$ normal saline. After the lungs on both sides and the liver of the rat were obviously whitened, $100 \mathrm{ml}$ paraformaldehyde was used for fixation, and the brain tissue of the rat was taken and continuously fixed in $4 \%$ paraformaldehyde for $24 \mathrm{~h}$, followed by gradient dehydration with 20 and $30 \%$ sucrose solutions, respectively. The brain tissue of the rat was sectioned, dehydrated, embedded in paraffin, sliced serially and coronally using a paraffin slicing machine, attached to a treated glass slide, and dried at $60^{\circ} \mathrm{C}$ for $2 \mathrm{~h}$. Then, Nissl staining was performed, that is, the section was dewaxed and hydrated, subjected to hyalinization and dehydration, washed with distilled water 3 times ( $3 \mathrm{~min} /$ time), and stained with $1 \%$ toluidine blue for $6 \mathrm{~min}$. Subsequently, the section was washed with distilled water 3 times ( $3 \mathrm{~min} /$ time), placed in $70 \%$ ethanol for $2 \mathrm{~min}$ and then $95 \%$ ethanol for $5 \mathrm{~min}$, and placed in absolute ethanol for color separation until the nucleus was light blue, and the background was colorless. The section was then immersed in xylene for $5 \mathrm{~min}$, mounted, and placed under a microscope (Olympus, Tokyo, Japan) for observation.

Measurement of adenosine triphosphate (ATP) level in hippocampus tissue. The level of ATP in the hippocampus tissue of each rat in two groups was measured by a rat ATP assay kit. The tissue was lysed by adding lysis buffer (ratio of tissue to lysis buffer: $100 \mathrm{mg}: 1 \mathrm{ml}$ ) and homogenized with an ultrasonic homogenizer under an ice bath until the tissue was completely lysed without macroscopic tissue fragments. Then, the tissue was centrifuged at $9,800 \times \mathrm{g}$ for $10 \mathrm{~min}$ at $4^{\circ} \mathrm{C}$, and the supernatant was collected and stored at $-20^{\circ} \mathrm{C}$ for subsequent experiments. ATP test solution $(100 \mu \mathrm{l})$ was added into a standard tube and a detection tube in the dark, and then the two tubes were placed at room temperature for $5 \mathrm{~min}$ of reaction to degrade ATP. After that, ATP standard substance with different concentrations was added into the standard tube, quickly mixed and placed on a microplate reader (Bio-Rad Laboratories, Inc., Hercules, CA, USA) to determine the relative light unit (RLU) and counted photons per minute (CPM) values of the sample and a standard curve was drawn; different sets of samples were added to the detection tube, and ATP concentration in the sample was measured using a microplate reader.

Ribonucleic acid (RNA) extraction and quantitative polymerase chain reaction ( $q P C R$ ). After the rat hippocampus tissue was obtained, the tissue $(100 \mathrm{mg})$ was added with TRIzol lysis solution $(1 \mathrm{ml})$ for homogenization in the ice bath, added with $300 \mu \mathrm{l}$ chloroform, and thoroughly mixed. Then, the tissue was placed on ice for $10 \mathrm{~min}$ and centrifuged at 9,800 $\mathrm{x}$ g and $4^{\circ} \mathrm{C}$ for $15 \mathrm{~min}$. After separation of the supernatant, an equal amount of isopropanol was added, placed at room temperature for $5 \mathrm{~min}$, and centrifuged at $4^{\circ} \mathrm{C}$ and $9,800 \mathrm{x} \mathrm{g}$ for $10 \mathrm{~min}$. The supernatant was discarded, and $1 \mathrm{ml} 75 \%$ ethanol was added for washing, followed by centrifugation at $4^{\circ} \mathrm{C}$ and $9,800 \mathrm{x} \mathrm{g}$. After that, the supernatant was discarded, $50 \mu \mathrm{l}$ diethylpyrocarbonate (DEPC) water was added for dissolution, and then RNA was obtained. The optical density (OD) value and RNA integrity were then tested, and RNA was stored at $-20^{\circ} \mathrm{C}$ until use. The RNA was reverse transcribed into complementary deoxyribonucleic acid (cDNA) using a reverse transcription kit, acting as a template. After adding $\mathrm{qPCR}$ reaction system, the reaction was carried out under the following conditions: 
Table I. PCR primers.

\begin{tabular}{ll}
\hline Gene & \multicolumn{1}{c}{ Sequence } \\
\hline Fatty acid & F: 5'-AGGCTAACCCCACTCTATGAATC-3' \\
synthetase (Fas) & R: 5'-TCTTGCCTTTGGTGGACTA-3' \\
Fas ligand (FasL) & F: 5'-AGAGGAACCACAGCACA-3' \\
& R: 5'-TCACTCCAGAAAGCAGGACA-3' \\
Caspase-3 & F: 5'-ATGGACAACAACGAAACCTC-3' \\
& R: 5'-TTAGTGATAAAAGTACAGTTCTT-3' \\
D-loop & F: 5'-AATCTACCATCCTCCGTG-3' \\
& R: 5'-GACTAATGATTCTTCACCGT-3' \\
GAPDH & F: 5'-CAGTGCCAGCCTCGTCTCAT-3' \\
& R: 5'-AGGGCCATCCACAGTCTTC-3'
\end{tabular}

GAPDH, glyceraldehyde-3-phosphate dehydrogenase; F, forward; $\mathrm{R}$, reverse.

$95^{\circ} \mathrm{C}$ for $10 \mathrm{sec}, 95^{\circ} \mathrm{C}$ for $5 \mathrm{sec}, 60^{\circ} \mathrm{C}$ for $15 \mathrm{sec}$ and $72^{\circ} \mathrm{C}$ for $15 \mathrm{sec}$, with 39 cycles in total, and then $72^{\circ} \mathrm{C}$ for $5 \mathrm{sec}$ and $95^{\circ} \mathrm{C}$ for $2 \mathrm{~min}$ to stop the reaction. Glyceraldehyde-3-phosphate dehydrogenase (GAPDH) was used as internal reference. The expression level of the corresponding gene was calculated by the $2^{-\Delta \Delta C \mathrm{q}}$ method (12). The primers were synthesized by Tiangen Biotech Co., Ltd. The sequences are shown in Table I.

Western blot analysis. The rat hippocampus tissue was collected and added with lysis solution for homogenization until no macroscopic tissue was observed and then, centrifuged at 9,800 x $\mathrm{g}$ at $4^{\circ} \mathrm{C}$ for $10 \mathrm{~min}$. The supernatant was removed and the total protein concentration in the hippocampus tissue was measured using a bicinchoninic acid (BCA) protein assay kit. Sample loading system with the same concentration was prepared, and the sample was loaded. Sodium dodecyl sulfate polyacrylamide gel electrophoresis (SDS-PAGE) was applied to separate protein, and then protein was transferred onto a polyvinylidene fluoride (PVDF) membrane under a constant pressure of $90 \mathrm{~V}$ and blocked with newly prepared 5\% non-fat dry milk for $2 \mathrm{~h}$. After that, target band was cut down based on the size of protein band, and incubated with rabbit anti-rat fatty acid synthetase (Fas), Fas ligand (FasL), caspase-3 and GAPDH polyclonalantibodies (1:1000; cat. nos.: ab82419, ab15285, ab13847,ab9485; Abcam; Cambridge, MA, USA) at $4^{\circ} \mathrm{C}$ overnight. Then, the band was washed with Tris-buffered saline with Tween ${ }^{\circledR}-20$ (TBST) 5 times (5 min/time), and incubated with goat anti-rabbit secondary polyclonal antibody (1:1200; cat. no.: ab6721; Abcam) at room temperature for $2 \mathrm{~h}$, and washed with TBST 3 times (10 min/time). Electrochemiluminescence (ECL) mixture was prepared, followed by tableting in the dark. Then, luminescence solution was added for color development, and film was dried, and subjected to software processing. Fas/GAPDH, FasL/ GAPDH and caspase-3/GAPDH indicated the relative expression levels of proteins in each group.

Statistical analysis. Data in this study are expressed as mean \pm standard deviation. Statistical Product and Service Solutions (SPSS) 19.0 software (SPSS Inc., Chicago, IL, USA)
Table II. Scores for epileptic seizures.

\begin{tabular}{lrrccc}
\hline Groups & I & II & III & IV & V \\
\hline Control group (n) & 13 & 2 & 0 & 0 & 0 \\
Model group (n) & 0 & 0 & 1 & 5 & 9 \\
P-value & & & & $<0.05$ & $<0.05$ \\
t-value & & & & 0.586 & 0.678 \\
\hline
\end{tabular}

was employed for data analysis. Student's t-test was used for comparisons between two groups. Pearson's analysis was adopted for inter-factor correlations. $\mathrm{P}<0.05$ suggested that the difference was statistically significant.

\section{Results}

Evaluations of epileptiform symptoms in rats. After rats in both groups received inducing treatment, symptoms such as perspiration, piloerection and eye congestion were observed at approximately $10 \mathrm{~min}$ after modeling in rats of the model group, and epileptiform behavior of rats was evaluated via Racine seizure scale. The results revealed that modeling was successful in 15 rats, with typical epileptiform symptoms, and all rats in the control group had typical epileptiform symptoms (Table II). EEG was applied to detect epileptic rat cluster spike discharge. The results indicated that typical cluster spike discharge was found in the hippocampus of rats in the model group, and no abnormal discharge was observed in the rats in control group (Fig. 1).

Injuries in hippocampal neurons. Nissl staining was used to detect the injuries in hippocampal neurons of rats in the two groups. As shown in Fig. 2, the hippocampal neurons of rats in the control group had compact arrangement, complete cell morphology, clear cell structure and abundant Nissl bodies in the cytoplasm, and the hippocampal neurons of rats in the model group were loosely arranged, with fuzzy cell outline, shrunken cell body, pyknotic nuclei, and significantly reduced Nissl bodies in cytoplasm. It meant that hippocampal neurons in rat models of epilepsy had severe damage.

Detection of mitochondrial function in hippocampal neurons. ATP levels and mitochondrial DNA levels in hippocampus tissues of rats in both groups were measured to evaluate the mitochondrial function of hippocampal neurons. According to Fig. 3, both ATP level and mitochondrial DNA level in hippocampus tissue of the rat in the model group were significantly lower than those in the control group $(\mathrm{P}<0.01)$.

Measurements of mRNA and protein expression levels. The expression levels of related genes in hippocampus tissues of rats in two groups were detected by qPCR. The results revealed that mRNA expression levels in hippocampus tissue of the rat in the model group were overtly higher than those in the control group $(\mathrm{P}<0.01)$ (Fig. 4). Western blotting was used to detect related protein expression levels in hippocampus tissue of rats in the two groups. The results showed that protein expression levels in hippocampus tissue of the rat in the model 

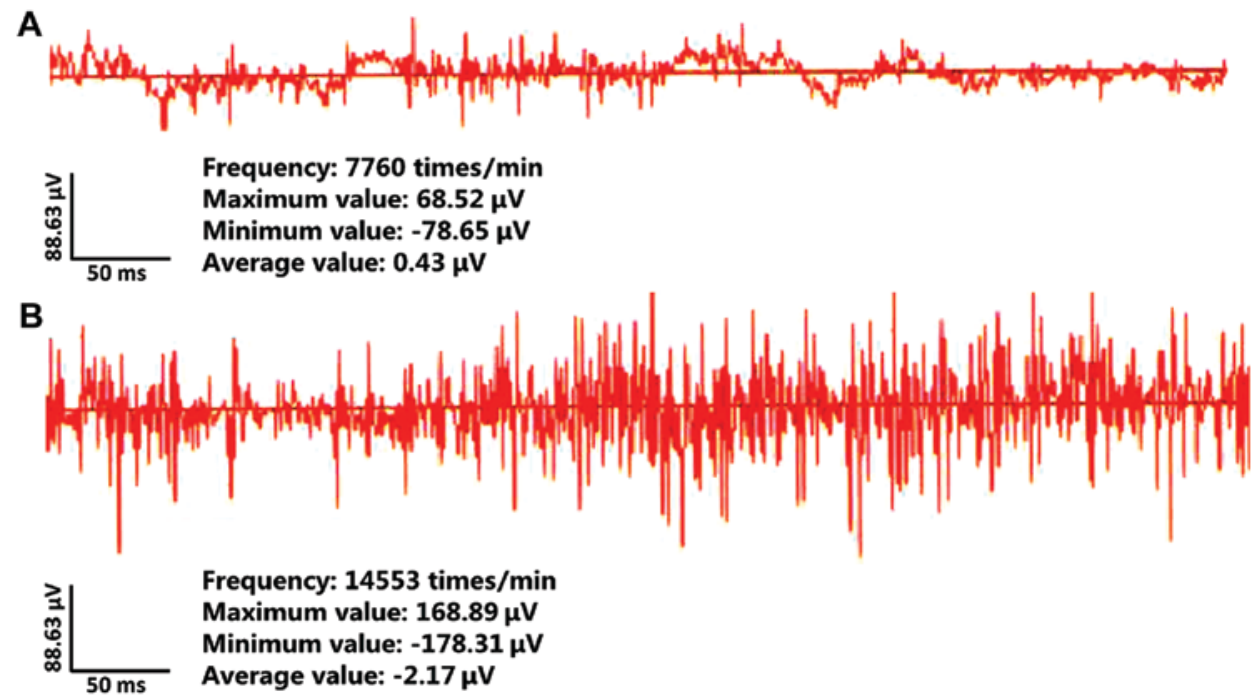

Figure 1. Paradoxical discharge of hippocampal neurons in rats detected via EEG. (A) Brain waves of rats in the control group. (B) Brain waves of rats in the model group, where typical cluster spike discharge was found. EEG, electroencephalogram.
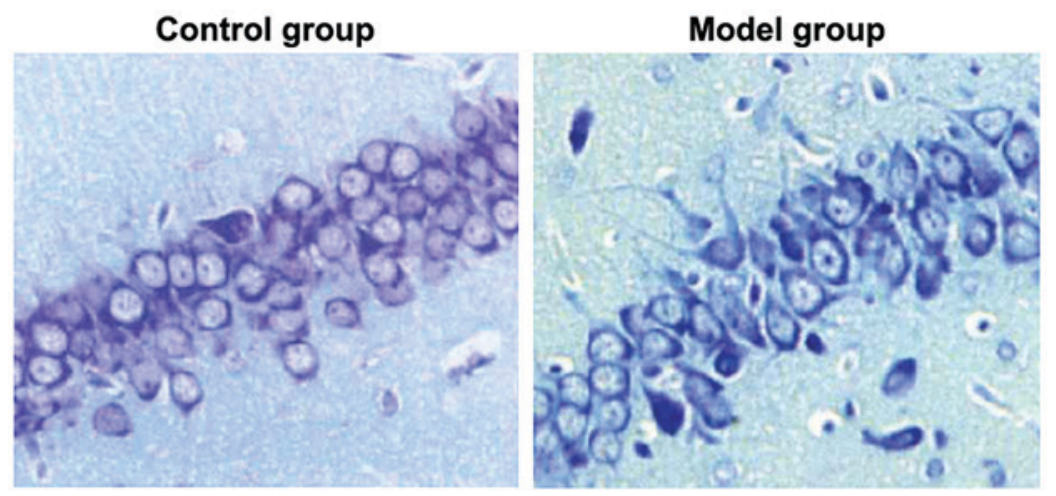

Figure 2. Injuries of hippocampal neurons of rats in two groups detected through Nissal staining. Blue refers to nuclei. The hippocampal neurons of rats in control group are compactly arranged, with complete cell morphology; the hippocampal neurons of rats in model group are loosely arranged, with fuzzy cell outline.
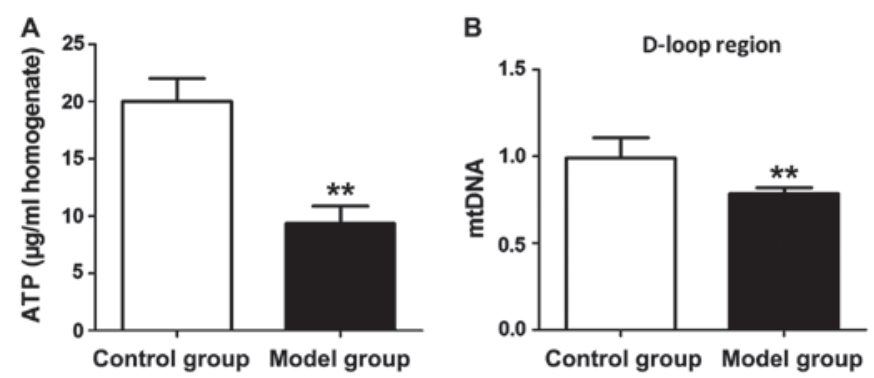

Figure 3. Evaluation of mitochondrial function in hippocampal neurons. (A) Measured ATP levels in hippocampus tissue. (B) Expression levels of mitochondrial DNA in hippocampus tissue: model group has obviously decreased ATP level and mitochondrial DNA level in rat hippocampus tissue in comparison with the control group; ${ }^{* *} \mathrm{P}<0.01$.

group were increased evidently compared with those in the control group $(\mathrm{P}<0.01)$ (Fig. 5). Western blot results show the expression of Fas, FasL and caspase-3 protein is consistent with mRNA expression.

Correlation analysis. Pearson's analysis was used to detect the correlations of mitochondrial dysfunction with the expression of Fas and caspase-3. As shown in Fig. 6, mitochondrial DNA level in rat hippocampal neurons was negatively correlated with the protein expression of Fas and caspase-3 $\left(r^{2}=222, \mathrm{P}<0.05\right)$.

\section{Discussion}

Numerous studies have suggested that phases of epilepsy induction and epilepticus are able to lead to changes in neuronal ultramicro results, resulting in mitochondrial dysfunction. A study by Chang et al (13) found that induction of epilepticus in rats can significantly reduce the activities of reduced form of nicotinamide-adenine dinucleotid (NADH) cytochrome $c$ reductase and aconitase in hippocampus, and with the alleviation of symptoms of epilepsy, enzyme activities in vivo will gradually recover. A study by McDonald et al (14) discovered that obvious structural changes are observed in mitochondria of hippocampal neurons during epileptic seizures, which may be manifested as rupture of membrane and reduction of transmembrane potential. Epileptic seizures are often accompanied by anomalies in oxygenic respiratory chain complex I, resulting in massive electron leakage, thereby producing reactive oxide species and damaging nerve cells. 

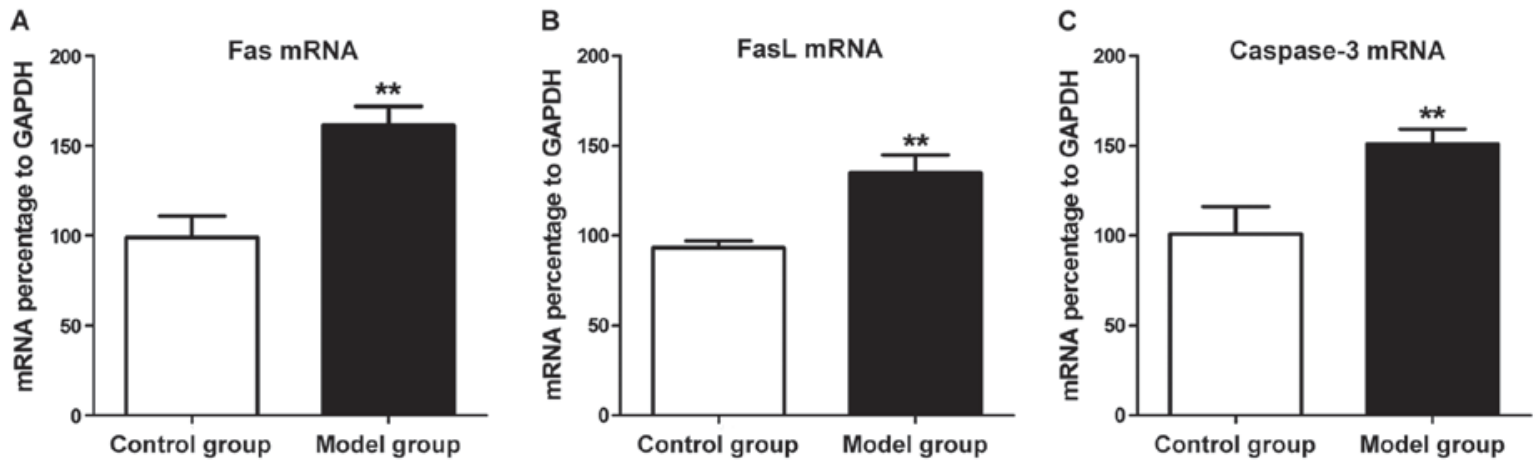

Figure 4. Fas, FasL and caspase-3 mRNA levels in hippocampus tissues of rats with epilepsy detected by quantitative polymerase chain reaction (qPCR). (A) Fas, (B) FasL and (C) caspase-3 mRNA expression levels in rat hippocampus tissue in model group are distinctly greater than those in control group, ${ }^{* * *} \mathrm{P}<0.01$.
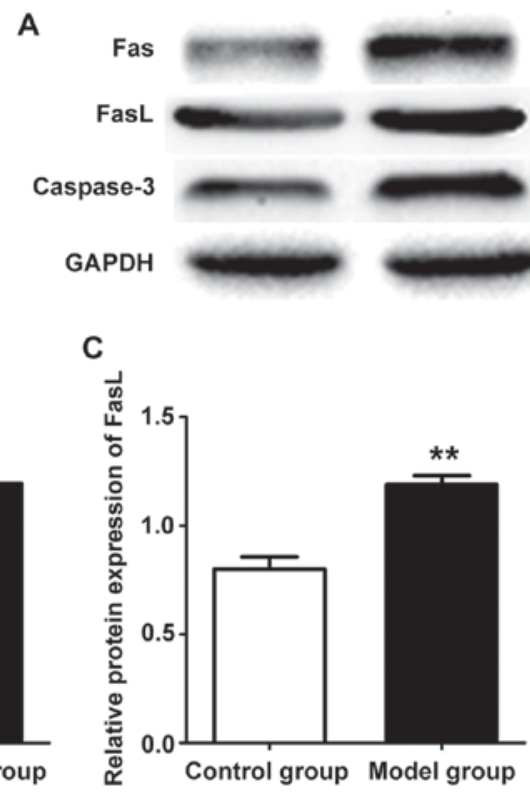

D
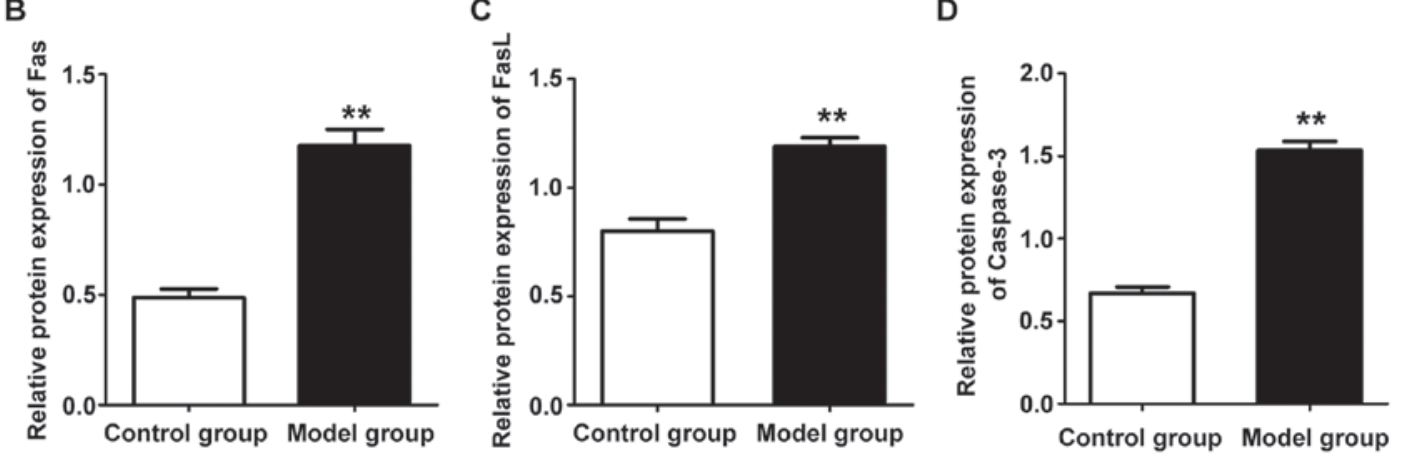

Figure 5. (A) Protein levels of Fas, FasL and caspase-3 in hippocampus tissues of rats with epilepsy detected by western blotting. (B) Fas, (C) FasL and (D) caspase-3 protein expression levels in rat hippocampus tissue in model group are clearly higher than those in control group, ${ }^{* *} \mathrm{P}<0.01$.
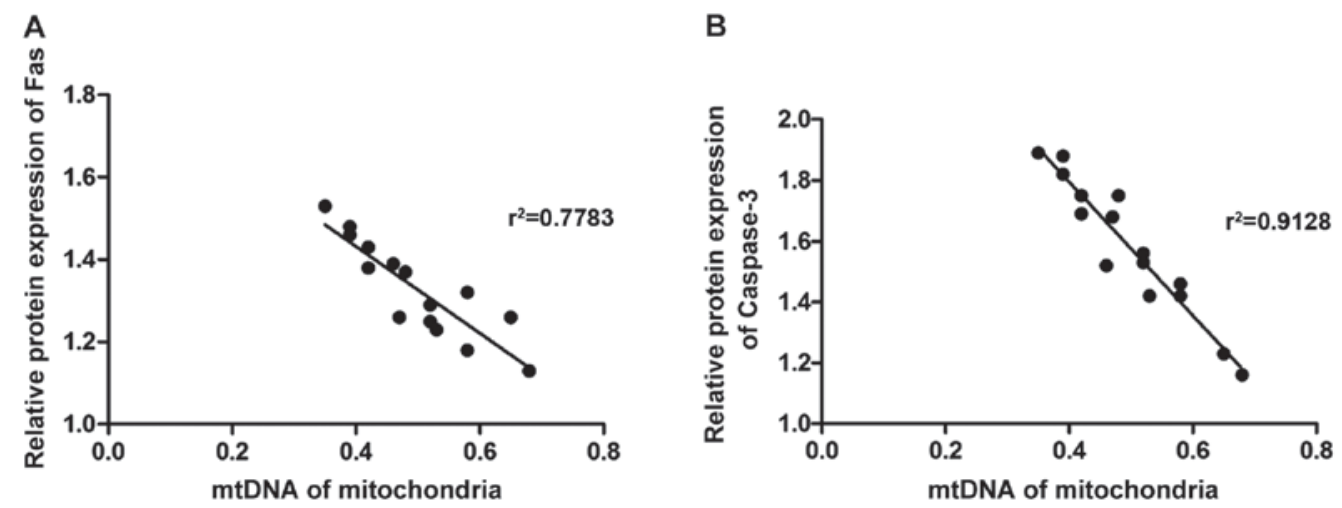

Figure 6. Correlation analysis. Mitochondrial DNA level in rat hippocampal neurons is negatively correlated with the protein expression levels of (A) Fas and (B) caspase-3.

In addition, seizures can overtly increase the oxidative stress response and further aggravate mitochondrial damage. The above changes are likely to result in decreased mitochondrial activity, affect mitochondrial transcription and translation processes, and lead to neuron necrosis at epilepsy sites due to a serious shortage of ATP (15). In this study, intraperitoneal injection of lithium chloride-pilocarpine was carried out to induce epilepticus in rats, a large number of necrotic hippo- 
campal neurons were found in epileptic rats through Nissal staining, and the simultaneous detections of ATP level and mitochondrial DNA level in hippocampus tissues revealed that mitochondria in hippocampus tissue had obvious damage. The results are consistent with the corresponding reports. As a cholinergic receptor agonist, pilocarpine can excite M-type cholinergic receptors to cause excited paradoxical discharge of neurons, thereby effectively simulating the cause of seizures and establishing rat models of epilepsy. The modeling method is widely used because it has high safety, clear epileptogenic process, obvious symptoms of induced epilepsy, and humanlike behavior and changes of EEG (16).

Mitochondrion can mediate the occurrence of apoptosis, Fas is a membrane protein involved in the process of apoptosis, whose ligand is FasL, and the combination of the two can form a trimer with apoptosis-inducing activity (17-19). A study of $\mathrm{Hu}$ et al (20) showed that Fas/FasL is able to regulate apoptosis through Fas-associated protein with death domain (FADD), and the activation of FADD will lead to obviously increased expression and activation of caspase- 8 in cells. Activated caspase- 8 can further activate caspase-3, leading to caspase cascade reaction and thus resulting in apoptosis (21). This study found that both mRNA and protein expression levels of Fas and FasL in hippocampus tissue of epileptic rats were significantly increased, indicating that the occurrence of epilepsy can activate Fas/FasL signaling pathway, and further study found that caspase-3 expression level was also evidently elevated. The results suggest that epilepsy-induced neuronal apoptosis is caused by Fas/FasL pathway via FADD. Correlation analysis was used to evaluate the relationships between the expression levels of Fas and caspase- 3 and mitochondrial dysfunction. The results showed that there were negative correlations between the expressions of Fas and caspase-3 and the level of mitochondrial DNA, that is, mitochondrial dysfunction was closely related to the signaling pathway.

In conclusion, the occurrence of epilepsy in rats may lead to mitochondrial dysfunction in rat hippocampal neurons, thus resulting in apoptosis of hippocampal neurons, which may be realized through activating Fas/FasL signaling pathway and increasing caspase-3 expression.

\section{Acknowledgements}

Not applicable.

\section{Funding}

No funding was received.

\section{Availability of data and materials}

The datasets used and/or analyzed during the current study are available from the corresponding author on reasonable request.

\section{Authors' contributions}

JF determined epileptiform behavior. LF performed western blot analysis. JF and GZ helped with Nissal staining. All authors have read and approved the final manuscript.

\section{Ethics approval and consent to participate}

The provisions for experimental animals in the Guide for the Care and Use of Laboratory Animals by the National Research Council were strictly abided in all operations on animals. The experimental scheme was approved by the Experimental Animal Ethics Committee in Daqing Longnan Hospital (Daqing, China).

\section{Patient consent for publication}

Not applicable.

\section{Competing interests}

The authors declare that they have no competing interests.

\section{References}

1. Sahoo SS, Lhatoo SD, Gupta DK, Cui L, Zhao M, Jayapandian C, Bozorgi A and Zhang GQ: Epilepsy and seizure ontology: Towards an epilepsy informatics infrastructure for clinical research and patient care. J Am Med Inform Assoc 24: 82-89, 2014.

2. Liu J, Reeves C, Michalak Z, Coppola A, Diehl B, Sisodiya SM and Thom M: Evidence for mTOR pathway activation in a spectrum of epilepsy-associated pathologies. Acta Neuropathol Commun 2: 71, 2014.

3. Speed D, O'Brien TJ, Palotie A, Shkura K, Marson AG, Balding DJ and Johnson MR: Describing the genetic architecture of epilepsy through heritability analysis. Brain 137: 55-69, 2014.

4. Kaiboriboon K, Bakaki PM, Lhatoo SD and Koroukian S: Incidence and prevalence of treated epilepsy among poor health and low-income Americans. Neurology 80: 1942-1949, 2013.

5. Ying Z, Najm I, Nemes A, Pinheiro-Martins AP, Alexopoulos A, Gonzalez-Martinez J and Bingaman W: Growth-associated protein 43 and progressive epilepsy in cortical dysplasia. Ann Clin Transl Neurol 1: 453-461, 2014.

6. Wirrell EC, Grossardt BR, Wong-Kisiel LC and Nickels KC: Incidence and classification of new-onset epilepsy and epilepsy syndromes in children in Olmsted County, Minnesota from 1980 to 2004: A population-based study. Epilepsy Res 95: 110-118, 2011.

7. Bowen JM, Snead OC, Chandra K, Blackhouse G and Goeree R: Epilepsy care in Ontario: An economic analysis of increasing access to epilepsy surgery. Ont Health Technol Assess Ser 12: 1-41, 2012.

8. Bardai RJ, Lamberts RJ, Blom MT, Spanjaart AM, Berdowski J, van der Staal SR, Brouwer HJ, Koster RW, Sander JW, Thijs RD, et al: Lamberts, marieke T. epilepsy is a risk factor for sudden cardiac arrest in the general population. PLoS One 7: 14-23, 2012.

9. Kovac S, Dinkova Kostova AT, Herrmann AM, Melzer N, Meuth SG and Gorji A: Metabolic and homeostatic changes in seizures and acquired epilepsy - mitochondria, calcium dynamics and reactive oxygen species. Int J Mol Sci 18: E1935, 2017.

10. Fahrner JA, Liu R, Perry MS, Klein J and Chan DC: A novel de novo dominant negative mutation in DNM1L impairs mitochondrial fission and presents as childhood epileptic encephalopathy. Am J Med Genet A 170: 2002-2011, 2016.

11. McFarland KN, Liu J,Landrian I,Zeng D, Raskin S, Moscovich M, Gatto EM, Ochoa A, Teive HA, Rasmussen A, et al: Repeat interruptions in spinocerebellar ataxia type 10 expansions are strongly associated with epileptic seizures. Neurogenetics 15: 59-64, 2014.

12. Livak KJ and Schmittgen TD: Analysis of relative gene expression data using real-time quantitative PCR and the $2^{-\triangle \Delta C T}$ method. Methods 25: 402-408, 2001.

13. Chang HJ, Liao CC, Hu CJ, Shen WW and Chen TL: Psychiatric disorders after epilepsy diagnosis: A population-based retrospective cohort study. PLoS One 8: e59999, 2013.

14. McDonald TS, Carrasco-Pozo C, Hodson MP and Borges K: Alterations in cytosolic and mitochondrial (U-13C)glucose metabolism in a chronic epilepsy mouse model. eNeuro: Mar 9, 2017 (Epub ahead of print). doi: 10.1523/ENEURO.0341-16.2017. 
15. Rowley S, Liang LP, Fulton R, Shimizu T, Day B and Patel M: Mitochondrial respiration deficits driven by reactive oxygen species in experimental temporal lobe epilepsy. Neurobiol Dis 75: 151-158, 2015

16. Meng DW, Liu HG, Yang AC, Zhang K and Zhang JG: Stimulation of anterior thalamic nuclei protects against seizures and neuronal apoptosis in hippocampal CA3 region of kainic acid-induced epileptic rats. Chin Med J (Engl) 129: 960-966, 2016.

17. Yamada A, Arakaki R, Saito M, Kudo Y and Ishimaru N: Dual role of Fas/FasL-mediated signal in peripheral immune tolerance. Front Immunol 8: 403, 2017.

18. Liu G, Yuan Y, Long M, Luo T and Bian J: Beclin-1-mediated autophagy protects against cadmium-activated apoptosis via the Fas/FasL pathway in primary rat proximal tubular cell culture. Sci Rep 8: 3941-3948, 2017

19. Zhou X, Hong T, Yu Q, Nie S, Gong D, Xiong T and Xie M: Exopolysaccharides from Lactobacillus plantarum NCU116 induce c-Jun dependent Fas/Fasl-mediated apoptosis via TLR2 in mouse intestinal epithelial cancer cells. Sci Rep 7: 14247, 2017.
20. Hu L, Chen L, Yang G, Li L, Sun H, Chang Y, Tu Q, Wu M and Wang H: HBx sensitizes cells to oxidative stress-induced apoptosis by accelerating the loss of Mcl-1 protein via caspase-3 cascade. Mol Cancer 10: 43, 2011.

21. Zhou X and Hong T: Exopolysaccharides from Lactobacillus plantarum NCU116 induce c-Jun dependent Fas/Fasl-mediated apoptosis via TLR2 in mouse intestinal epithelial cancer cells. Retrovirology 5: 14-35, 2008.

This work is licensed under a Creative Commons Attribution-NonCommercial-NoDerivatives 4.0 International (CC BY-NC-ND 4.0) License. 